\title{
Why are Latinos More Politically Trusting than Other Americans?
}

\author{
Marisa A. Abrajano and R. Michael Alvarez
}

\begin{abstract}
This paper examines why Latinos, over the past thirty years, are consistently more trusting of the federal government than are Anglos and Blacks. We address this puzzle by turning to previous research on racial politics and political trust. Consistent with previous research, discrimination and generational status are important predictors of Latinos' levels of political trust, with first generation Latinos more trusting than later generation Latinos. Encounters with racial discrimination also make Latinos and Blacks less trusting of government. In contrast, Anglos' levels of political trust can be explained by their economic evaluations as well as their partisanship. While these findings are insightful, they do not directly address why inter-group differences arise when it comes to their trust in government. We argue that, combined with generational distinctions amongst Latinos in their levels of trust, the heavy flow of Latino immigration in the past thirty years has changed the Latino population in such a way that the views of the foreign-born are disproportionately represented in survey questions related to trust in government. This is producing a Latino population that is more inclined to trust government than Anglos or Blacks. We then examine the impact of political trust on individuals' opinions towards redistributive policies. Political trust has a strong and positive effect on Latinos' attitudes towards such policies. These findings have important implications for the future of public opinion and redistributive policy-making in the U.S.
\end{abstract}

Abrajano is an Assistant Professor in the Department of Political Science, University of California San Diego, and is the corresponding author, (mabrajano@ucsd.edu). Alvarez is Professor of Political Science, Division of Humanities and Social Sciences, California Institute of Technology, (rma@hss.caltech.edu), and Senior Fellow, USC Annenberg Center for Communication. Abrajano would like to thank Zoltan Hajnal, Thad Kousser, Gerry Mackie, and Megumi Naoi for their comments and suggestions. 


\section{Introduction}

Over the past 35 years, many scholars have been concerned about a noticeable decline in the trust that Americans have in their government, a decline starting during the 1960's. The amount of trust one places in government also influences an individual's political attitudes and opinions (Baldassare 2004; Hetherington 1998, 1999, 2005). Yet what if Latinos, the fastest growing segment of the U.S. population, projected to make-up over a quarter of the population in less than twenty years, consistently possess higher rates of political trust than non-Latino Americans? What implications might this have on the landscape of American public opinion and political behavior? Interestingly enough, this is not a mere thought exercise, but an empirical puzzle of contemporary importance.

We motivate our study by looking first at the responses provided by Anglo, Black, and Latino respondents from the National Election Studies (NES) from 1964-2002, with respect to their trust in the federal government. ${ }^{1}$ Here we look at the standard question used to study political trust, which asks survey respondents whether they trust the people in Washington to do what is right. We graph in Figure 1 the responses to this question, using data from the NES, for White, Black and Latino NES respondents. ${ }^{2}$ Prior to 1972, the NES categorized Hispanic and Latino respondents into a residual ("other") category, so in Figure 1 we use the responses of all those classified as "other" before 1972 while after that we are able to more specifically use only the responses of those who were classified as only Hispanic or Latino.

\section{[Figure 1 Goes Here]}

This simple graph shows a number of interesting phenomenon. The primary result, which motivates our interest in this topic, is the observation that with only a few exceptions, the trust of Latino respondents in government is greater than that of both Anglo and Black respondents. While the changes over this span of data in the time-series for each racial/ethnic group are correlated, it is

\footnotetext{
${ }^{1} 1964$ is the first year in which the NES included this trust question.

${ }^{2}$ Sapiro, Virginia, Steven J. Rosenstone, and the National Election Studies. AMERICAN NATIONAL ELECTION STUDIES CUMULATIVE DATA FILE, 1948-2002 [Computer file]. 12th ICPSR version. Ann Arbor, MI: University of Michigan, Center for Political Studies [producer], 2004. Ann Arbor, MI: Inter-university Consortium for Political and Social Research [distributor], 2004.
} 
also the case that Latinos are generally more trusting of government than respondents from other racial/ethnic groups. Secondly, and worth separate discussion, is the fact that Latino respondents are generally more trusting than Black respondents - which we return to below, as it provides us an important opportunity to contrast the political experiences of Latino and Blacks regarding their orientation to American politics during this period. Third, we also note that examination of this data provided in Figure 1 shows that it is unclear that the dynamics of political trust for Anglos, Blacks or Latinos - yields readily to the sort of analyses that have been staple in the political trust literature. As we discuss below, most of the previous research on political trust has focused attention on the decline in political trust through the early 1980's; note that this graph indicates that the decline was reversed in the mid-1990's for all three racial/ethnic groups, and at least through 2002 political trust has been on the increase in the United States in the NES data.

The primary focus of this paper is to understand the political trust of Latinos, as compared to Anglos and Blacks. Drawing on the racial politics literature, where the bulk of the work focuses on the Black-White dichotomy, we might expect Latinos to possess levels of political trust comparable to Blacks; their status as racial minorities in America and the structural and political inequalities that follow, resulted in more cynical and pessimistic views toward government (Hero 1992). However, given the unique historical experience of Black Americans, a history in which Latinos do not share, this framework may not entirely explain why differences like those apparent in Figure 1 exist (Dawson 1994). The few empirical studies conducted in the political science literature find that immigrants who have not fully assimilated into American society are more trusting of government than those who are more assimilated in the American political system (Michelson 2001, 2003). Immigrants who are new to the American political system may not only perceive it as being better than their homeland government, but also give credence to the "American dream" and everything associated with this idea - freedom, democracy, and transparency. The provision of public goods may also serve as clear and positive signals to immigrants. As such, we would expect foreign-born immigrants to posses more optimistic and positive views of government than would later generation immigrants. 
Race scholars have also found experiences with racial discrimination to affect immigrants' political attitudes and behaviors (Michelson 2001, Michelson 2003, Portes and Rumbaut 1996, Garcia Bedolla 2005, Pantoja et al 2001). The selective disassociation or downward assimilation theory (Portes and Rumbaut 1996) suggests that immigrants who have experienced racial/ethnic discrimination in either their personal or daily lives are less likely to assimilate at rates comparable to immigrants with no experiences of racial/ethnic discrimination. Thus, we might expect immigrants who report being discriminated against due to their ethnicity to be less politically trustful than those with no experiences of discrimination. Such encounters may lead second- and later-generation Latinos to possess more pessimistic and negative views of American society and government, which in turn may lead to a dislike for big government, and government involvement in general (Garcia Bedolla 2005). But even if later generations do not experience discrimination, their longer presence in America (relative to their parents) may cause them to assimilate or acculturate into all aspects of American society; thereby adopting a more cynical and distrustful view of government. These theories, however, cannot fully explain the pattern for Latinos' rates of trust depicted in Figure 1. If Latinos were indeed assimilating at normal or predicted rates, then their levels of political trust should be similar to the levels of political trust for Anglos and Blacks. While these assimilation theories can explain the differences in levels of political trust within the Latino community, they cannot explain why Latinos are more trusting of government than are Anglos and Blacks.

We offer two reasons as to why Latinos' levels of political trust have been greater than Anglos and Blacks for the past thirty years. First, as the racial politics literature suggests, first generation immigrants tend to possess more optimistic and favorable views of the government than later generation immigrants. Thus when asked how much they trust the federal government, immigrants may be more positive and optimistic than non-immigrants. The second reason relates to immigration trends in the U.S. Focusing on approximately the same time period as the one for trust (1964-2000), the proportion of the Latino population that is foreign-born has continually increased. In 1970, only $19.9 \%$ of the Latino population was foreign-born, but by 2000 , almost half (45.5\%) of the Latino population in the U.S. was foreign-born. ${ }^{3}$ Therefore, along with generational differences

\footnotetext{
${ }^{3}$ These figures are from the "Historical Census Statistics on the Foreign-born Population of the United States:
} 
in immigrants' levels of political trust, the steady influx of foreign-born Latinos explain why, over time, Latinos have been more politically trusting than Anglos and Blacks.

Our first step at explaining these variations in political trust is to examine the determinants of trust in government for Latinos, Blacks and Anglos. We contend that even if assimilation or selective disassociation theory can explain Latinos' attitudes towards the government, we would still expect Latinos to be more politically trusting than Blacks or Anglos as a result of the steady rates of Latino immigration in the past thirty years. We then go on to explore how political trust influences individuals' attitudes towards policies that the government is directly responsible for (e.g. redistributive policies). We predict that Latinos' high levels of trust in government will make them more supportive of these policies than non-Latinos. The following section reviews previous research on political trust and political assimilation. We then discuss our research design and methods, followed by a section that presents our findings. We conclude by discussing the policy implications from our research, in particular, the future of public support for redistributive policies in the U.S.

\section{Political Trust in America}

Levi and Stoker broadly define trust as a relationship that "involves an individual making herself vulnerable to another individual, group or institution that has the capacity to do her harm or betray her $(2000,476)$." Political trust or trust in government, however, does not equate to the same type of trust that one might bestow upon a friend. Instead, one's trust in government may suggest a belief that the government or elected official possesses the ability to perform a good job (Hardin 2002). It can also be conceived of as a one-way form of trust, since it is the individual who trusts the political institution, with no expectations that the institution will reciprocate (Hardin 2002). Over the early span of the time-series data on political trust, we see that political trust hit its peak in 1964, followed by an overall decline. Scholars attribute this downward trend to events such as Vietnam, Watergate and the Civil Rights Movement (Markus 1979, Abramson 1983). But 1850-1990" by Campbell J. Gibson and Emily Lennon, Population Division, U.S. Bureau of the Census. 
even when the administrations responsible for these events changed, this decline still continued. As a result, scholars pointed to the growing cynicism of television news reporting as the reason for these decreasing levels of trust (Patterson 1994, Chan 1997). The electorate's negative evaluations of Congress, and by default, the national government, further contributed to this downward trend in political trust (Williams 1985, Feldman 1983).

Concern about the decline in political trust results from the belief that trust is intricately linked to political behavior. The conventional wisdom is that individuals who are more trusting should also be more likely to participate and to be involved in politics (Stokes 1962, Almond and Verba 1963). According to Putnam (2000), individuals who trust in their fellow citizens should be more willing to meet and interact with others than those with lower levels of trust. Those with high levels of trust should also be the ones that volunteer, participate in political events, and in general, be the most civically engaged. Despite the logic of this argument, little empirical support exists for the relationship between trust and participation. Rosenstone and Hanson (1993) find no difference in the likelihood of voting and levels of political interest amongst the most and the least trusting individuals. Miller (1974) reaches a similar conclusion, failing to observe a relationship in the decreasing turnout rates and low levels of government trust. However, Shingles (1981) finds that politically distrustful individuals participate in more policy-related politics than more politically trusting individuals.

Instead of focusing exclusively on the relationship between trust and political participation, Hetherington (2005) examines the importance of political trust in one's support for policies where risk or sacrifice on the part of the individual is involved, e.g. redistributive policies. Thus, political trust is a crucial determinant of public opinion when it pertains to policies that only benefit a small group in society (e.g. racial minorities, the poor). Anglo parents' support of affirmative action policies in the university admissions process provide a good test of Hetherington's argument. He finds that a parent's support for affirmative action is contingent on his/her level of political trust, since one has to have enough faith in the federal government's ability to implement these policies in an impartial and race-neutral manner. The importance of political trust, however, diminishes 
when it pertains to one's attitudes on policies that require little personal sacrifice or risk, such as social security and crime prevention. The implications of Hetherington's findings for our research question are timely and important. In approximately twenty years, the American public will largely be comprised of individuals who could directly benefit from redistributive policies, the reasons for which are discussed in the next section. Latinos are expected to make-up $25 \%$ of the U.S. population by 2025 (US Census Bureau 2002). If the trend presented in Figure 1 holds, where Latinos are more trusting of government than Anglos and Blacks, the overall public's attitudes towards redistributive policies may begin to gradually shift over the next two decades, as such policies would directly benefit a sizable portion of the U.S. population.

Turning to the factors that influence an individual's trust in government, one's political views and perceptions are more strongly associated with his/her level of political trust than socioeconomic status and demographic attributes ( Stokes 1962, Craig 1996, Citrin and Muste 1999, Hetherington 2005). An individual's partisanship, economic evaluations, policy satisfaction and retrospective assessments of the incumbent are the primary political factors that influence trust in government (Miller 1974, Citrin and Green 1986). The critical role of the media (Patterson 1993) personal qualities of the president (Citrin and Green 1986), times of war (Parker 1989), and major political scandals (Weatherford 1984) have also been found to influence an individual's trust in government.

Several studies have found differences in the levels of political trust between racial minorities and non-minorities, specifically between Blacks and Whites. For instance, Blacks are less trusting of the government than Anglos when it pertains to government's efforts at racial equality (Abramson 1983). Moreover, Shingles finds that political trust and efficacy play an important role in the participation rates of Blacks, though it depends on the particular policy issue. But why Blacks are less politically trusting than Latinos, as the trends from the NES data suggest, has not received much attention in the research literature. One reason may be that Blacks hold a more pessimistic outlook on the future of race relations as well as their future than Latinos, Whites and Asians (Hajnal and Baldassare 2001). Blacks are also the least satisfied of their job opportunities and local government efforts in the employment sector, when compared to the other three racial groups 
(Hajnal and Baldassare 2001). Given that race relations, civil rights, and employment are so closely linked with the actions of the federal government, this may help to explain why Blacks' levels of political trust are lower than those of Latinos.

While these research findings are important, they suffer from the conceptualization of race as a purely black-white dichotomy. ${ }^{4}$ As such, our knowledge of Latinos' attitudes towards government is quite limited. A local study conducted by Michelson (2001) finds that recent Puerto Rican immigrants in the Chicago area are more trusting of the government than are long-time Puerto Rican residents. Her research on Mexican Americans produce similar results, where the greater one's level of acculturation into American society, the lower their level of government trust (Michelson 2003). Moreover, a 2001 Public Policy Institute of California (PPIC) survey of California residents finds that American-born Latinos are less trusting of government than naturalized Latinos, a pattern that is consistent with the assimilation theory (Hajnal and Baldassare 2001). However, this survey finds that Latinos, overall, are more trusting of government than Blacks and Anglos. A similar pattern exists in the Latino National Political Survey (LNPS); while 25\% of the foreign-born Latino respondents always trust government to do what is right, only $7.3 \%$ of the American-born Latinos always trust government (de la Garza and DeSipio 1992). Unfortunately, these studies, and the data they are based upon, are limited by an insufficiently small sample of Blacks and Latinos for detailed comparative study. Others are limited by geographic constraints or by exclusively focusing on the Latino population, without comparing them to other racial or ethnic groups. Our analysis uses data from national surveys, with large samples of Anglos, Blacks and Latinos, so that we can statistically compare political trust across the three racial/ethnic groups.

\section{Assimilation, Discrimination, and Immigration Trends}

We argue that generational differences amongst Latinos, along with U.S. immigration trends, explain why they are more trusting of government than non-Latinos. Typically, the immigrant experience is described in terms of the classic political assimilation model, which focuses on socioe-

\footnotetext{
${ }^{4}$ The extremely limited number of Latinos interviewed in the NES could also be another potential reason.
} 
conomic factors as the primary determinant of political assimilation (Dahl 1961, Wolfinger 1974). This model associates increased levels of socioeconomic well-being with ones rate of integration into the political system. Based on this model, Latinos, over time, should grow to be more politically cynical and skeptical of the federal government, as these are the views held by most Americans. But when Latinos first arrive to the U.S., they may possess high levels of political trust for a number of reasons. As discussed earlier, the majority of immigrants from Latin America and Mexico immigrate to the U.S. for economic reasons (Portes and Rumbaut 1996), knowing full-well both the economic and quality of life opportunities available to them in America relative to their homeland. This optimistic outlook should go hand in hand with their beliefs about the American government, therefore causing first generation immigrants to hold the American government in high regard.

A more recent assimilation perspective argues that traditional conceptualizations of assimilation, such as an improvement in language skills and familiarity with cultural norms and customs, do not necessarily result in actual political assimilation (Greeley 1971; Glazer and Moynihan 1970; and Portes and Rumbaut 1996). Portes and Rumbaut (1996) refine these concepts in the creation of the segmented assimilation theory, where experiences of discrimination serve to reemphasize the distinctive nature of the ethnic group, and perpetuate ethnic patterns and customs. Empirical support for the segmented assimilation theory exists; Mexicans with higher socioeconomic status, longer residency in America, and encounters with discrimination in America, are less likely to assimilate (Hero 1992). Moreover, Garcia Bedolla (2005) finds that participation in electoral politics and trust in government decline by one's generational status. While first-generation Latinos strongly believe that the government should solve community problems like crime, education, and after school programs, later-generation Latinos view their own community as the primary way to resolve their issues and concerns. In fact, the most acculturated Latinos (third-generation or later), feel that the government could not be expected to solve the problems of Latinos. Such attitudes are formed, in part, as a result of their experiences with discrimination and their perceptions of the federal government's willingness to help their community (Garcia Bedolla 2005). Therefore, consistent with the assimilation theory, we expect Latinos who experience discrimination to be less trusting of government than those with no experiences of discrimination. 
These theories of assimilation need to be considered in light of American immigration trends over the past 30 years. As Figure 2 demonstrates, the percentage of immigrants originating from Latin America has gradually increased from 1970-2000. This means that the foreign-born (or first generation) segment of the Latino population is constantly being replenished. While less than $20 \%$ of the Latino population in 1970 were foreign-born, there has been a steady increase through 2000 — in 2000, the foreign-born component of the Latino population is over $45 \% .^{5}$

\section{[Figure 2 Goes Here]}

If foreign-born Latinos are more trusting than later generation Latinos, then over time we would expect a larger and larger share of the Latino population to view the American government in a positive manner. This explanation would be consistent with the pattern that emerges from the NES data, presented in Figure 1. These foreign-born Latinos may have also had little to no experiences with discrimination, as this generally does not occur until the second generation (Portes and Rumbaut 1996). But even if Latinos experienced discrimination, the constant influx of new Latino immigrants would dominate opinions from later-generation Latinos in surveys. As such, analysis of Latino public opinion might predominantly come to reflect the views of the foreign-born population. The following section outlines our research design, followed by a discussion of the results emerging from our analysis.

\section{Hypotheses and Research Design}

We seek to address two questions. First, we are interested in understanding the determinants of political trust for Anglos, Blacks and Latinos. By doing so, we can explain why inter-group differences exist in their levels of political trust. We go on to examine whether political trust explains Latinos' policy attitudes, and in particular, their opinions on redistributive policies. Based on the segmented assimilation model, we expect individuals who have experienced racial discrimination to hold less favorable views of the government, relative to those with no experiences of discrimination.

\footnotetext{
${ }^{5}$ These figures are from the "Historical Census Statistics on the Foreign-born Population of the United States: 1850-1990" by Campbell J. Gibson and Emily Lennon, Population Division, U.S. Bureau of the Census.
} 
We also predict that, for Latinos, their generational status will influence their views towards government; later-generation Latinos, particularly those with the longest presence in America, should be less politically trusting than first-generation Latinos. In terms of the relationship between political trust and policy attitudes, we expect political trust to positively influence Latinos' attitudes towards redistributive policies. In our analysis, we use two different sources of data to test these two hypotheses.

First, we test the hypotheses pertaining to the determinants of political trust primarily using data from the 2002 Pew Hispanic Center and the Kaiser Family Foundation National Survey of Latinos. This telephone survey took place from April 4 to June 11, 2002, and is comprised of a nationally representative sample of randomly-selected individuals 18 years and older. Altogether, more than 2,900 Latinos (comprised of individuals from Mexico, Cuba, Puerto Rico, and Central and South America) are interviewed, as well 1,284 non-Latinos. The survey includes the most general question pertaining to political trust; it asks respondents how much they "trust the government in Washington to do what is right". The possible responses are just about always, most of the time, some of the time, and never. This measure of trust serves as our dependent variable, and given its ordinal nature, we use ordered logit analysis.

The independent variables used in this analysis control for the respondent's demographics, political beliefs, and economic evaluations. More specifically, one's marital status, partisanship, education and income level, gender and age are accounted for. We code marital status as a dummy variable, with a "1" indicating that the respondent is married, 0 otherwise. One's gender is coded in the same manner, where a " 1 " indicates that the respondent is a woman, 0 for male. Age is treated as a continuous variable, ranging from young to old. We create three dummy variables for low, medium and high income, with high income being the omitted category. We also create three dichotomous variables capturing the respondent's level of education: no high school degree, high school degree and some college or beyond. The latter category serves as the baseline. In light of previous research finding that one's political views, especially those of the current administration, influences their trust in government (Craig 1996, Citrin and Muste 1999), we control for 
a respondent's economic evaluations by using a question asking them about their pocketbook finances. Respondents were asked whether their current financial situation, compared to a year ago, was better, the same or worse. Each of the responses are coded as dummy variables, with those responding that their financial situation was worse being the omitted category. We also control for a respondent's experience with racial discrimination within the past five years to account for the segmented assimilation model. In addition, we account for instances when a respondent faced workplace discrimination (e.g. promotion or hiring) because of their ethnic or racial background. Encounters with discrimination, especially of the job-related kind, may cause Latinos and Blacks to be less trusting of the government in general when compared to those who have not experienced any racial discrimination, since they may feel that government efforts to resolve this problem have been ineffective.

Finally, for Latino respondents, we control for their generational status. One's nativity is determined by their parents' birthplace, along with their own place of birth. Latinos who are not born in the U.S. are considered to be first-generation, and those who are born in the U.S. but whose parents are born elsewhere are referred to as second-generation. Third-generation Latinos are those born in the U.S. as well as their parents. Those possessing fourth-generation status indicate that they, their parents as well as their grandparents are U.S. born. We generate four dummy variables to capture generational status, with the baseline category being first-generation respondents. In order to compare the effect of the independent variables on political trust for each ethnic/racial group, we estimated this model separately on Latinos, Anglos and Blacks. ${ }^{6}$

We then estimate a model that examines the impact of political trust on Latinos' attitudes toward redistributive policies, since we are interested in the potential implications that Latinos' high levels of political trust may have on the future American political landscape. Focusing redistributive policies allows us to test Hetherington's (2005) central findings that political trust plays an important role when it pertains to policies that the government is responsible for, and also those

\footnotetext{
${ }^{6}$ We also ran a pooled model interacting each of the independent variables with the respondent's ethnicity (Anglo and Latino). A Chow-test of this pooled model yielded an F test statistic of 15.25, which is statistically significant a the $p<.01$ level.
} 
where the benefit goes to a specific group. However, for this test, we use data from the National Annenberg Election Survey (NAES 2004), which interviewed a sizable number of Latinos and nonLatinos prior to the 2004 general election (Romer et al. 2006). ${ }^{7}$ While the survey did not include a specific question pertaining to welfare, several redistributive questions are available. These questions focused on a respondent's support/opposition to: 1) "the federal government trying to reduce the income differences between rich and poor Americans"; 2) "the federal government giving tax credits or vouchers to help parents send their children to private schools"; 3) "providing financial assistance to public elementary and secondary schools - should the federal government spend more on it, the same as now, less, or no money at all?"; 4) "providing health insurance for people who do not already have it- should the federal government spend more on it, the same as now, less, or no money at all?" Individuals' responses to the first two questions ranged from strongly oppose, somewhat oppose, neither favor or oppose, somewhat favor, and strongly favor. For these two questions, we create dummy variables, with a " 1 " indicating those who oppose the policy and "0" for those who are in support of the policy. The third and fourth questions offered respondents with four choices (more, the same, less or none). We again create dummy variables with a "1" indicate those who favor less or no federal spending, and a " 0 " for those who favor either the same or more spending by the federal government. These four questions serve as the dependent variables of our model and we estimate each using logit analysis.

Clearly, the first question most directly captures an individual's attitudes towards redistributive policies and it also requires a large amount of sacrifice on the part of the individual, as those who would reap the benefits are concentrated to a few. The remaining three questions are also redistributive in nature, though the amount of sacrifice is less, since more individuals would reap the benefits from such policies. There is little doubt that a large percentage of Latinos would benefit from these redistributive efforts. Slightly more than twenty-two percent of Latinos currently live

\footnotetext{
${ }^{7}$ The NAES was conducted by Daniel Romer, Kate Kenski, Kenneth Winneg, Christopher Adasiewicz, and Kathleen Hall Jamieson of the Annenberg Public Policy center of the University of Pennsylvania. While using the National Election Survey would allow us to compare our results more directly with Hetherington's, very few Latinos are interviewed each year. For instance, 89 respondents were interviewed who were of Hispanic/Latino descent in 2002. In 2000, the number interviewed was only slightly higher at 113. From 1972-2002, a total of 1,399 Latinos were interviewed by the NES.
} 
in poverty, while $32.7 \%$ lack health insurance (U.S. Census Bureau 2002). ${ }^{8}$ A greater amount of federal funding towards public education as well as school tax credits/vouchers would also assist Latinos, given that the gap in per pupil funding between minority and white school districts is more than $\$ 1,000$ (Carey 2003); thus a greater amount of federal assistance could improve the schools Latino students attend or they could turn to tax credits/vouchers as alternatives to public education. Based on Hetherington's argument, we expect Latinos' high levels of political trust, along with the fact that they would be the main beneficiaries from these redistributive policies to make them more supportive of these policies than non-Latinos.

Our main independent variable of interest in this analysis is political trust, which is coded as a categorical variable ranging from never to always trusting the government in Washington to do what is right. To determine whether a Latino's high levels of trust influences his/her attitudes towards redistributive policies, we include an interaction term for a Latino respondent and his/her level of political trust. We also control for a respondent's demographics and political attitudes. Of course, one's political affiliation may impact their views on these policies; thus we create dummy variables indicating a respondent's partisanship as Republican, Democrat or Independent, with those responding as Independents being the comparison group. We also account for a respondent's ideology, ranging from very conservative to very liberal. Along with these political variables, a respondent's socioeconomic status may influence their attitudes towards redistribution. We include several dummy variables to indicate a respondent's educational level and their income category. ${ }^{9}$ Age and gender are also controlled for, with age being a continuous variable and gender coded as a "1" for female, "0" for male. Finally, we account for a respondent's economic evaluations, as these could potentially influence their support or opposition to redistributive policies (Hetherington 2005).

\footnotetext{
${ }^{8}$ http://www.cbpp.org/8-29-06health.htm

${ }^{9}$ These variables were coded in the same manner as the previous model.
} 


\section{Findings}

We present our analyses in the following order. First, we examine how political trust varies with ethnicity, and for Latinos, how it varies across generational status, using both the 2002 Pew and 2004 NAES surveys. We follow this simple presentation of the data with our multivariate models that test for both hypotheses. The first set of analyses examines the determinants of political trust for Anglo, Black and Latino respondents; we follow that analysis and discussion with our multivariate analysis of the factors influencing Latinos' redistributive policy attitudes.

\subsection{Political Trust by Race, Ethnicity, and Generational Status}

Table 1 gives a snapshot of respondents' attitudes towards government, by their ethnicity and generational status in 2002, using the Pew Hispanic Survey data; Table 2 presents respondents' trust in government and and elected officials in 2004, using the NAES data. Consistent with the temporal pattern depicted in Figure 2, a greater percentage of Latinos always trust government to do what is right, relative to the other ethnic/racial groups in both 2002 and 2004. Likewise, the percentage of Latinos in 2002 who never trust government to do what is right is smaller than the percentage for White, Black, Asian and "other race" respondents (3.2\% versus $3.4 \%, 7.3 \%, 5.8 \%$, 8.7\%, respectively). As a point of comparison, the other large immigrant population in the U.S., Asian Americans, are not as politically distrustful as Blacks, but are more distrusting than Latinos in $2002 ; 5.8 \%$ of Asians never trust government to do what is right, compared with $3.2 \%$ for Latinos and $7.3 \%$ for Blacks. Additionally, when we examine the other two questions on government's role in society, we again see that Latinos are more trusting and supportive of government than members of any other racial or ethnic group: $68.4 \%$ of Latinos stated that they prefer more taxes and a bigger government, and $59.9 \%$ stated that a bigger government is better for the provision of public services. The 2004 Annenberg survey also includes a question pertaining to an individual's trust in the honesty of elected officials. As the distribution from Table 2 demonstrates, Hispanics and Asians are more trusting of the honesty of their elected officials than Whites and Blacks. Consistent with their levels of trust in government, we see that Blacks are the least trusting of politicians (15.9\%), 
when compared to the other three racial groups.

\section{[Tables 1- 3 Go Here]}

By comparing the rates of political trust for the three dominant racial groups in the U.S. using both the 2002 Pew and the 2004 NAES data, we see again that Latinos are the most politically trusting, followed by Asians and Blacks. While one may have expected Asian Americans to follow the same trajectory as Latinos, since both groups share in the immigrant experience, it appears that they are not as trustful as Latinos. Why this is the case is not entirely clear, but perhaps generational status does not explain their levels of political trust as well as it does for Latinos. ${ }^{10}$ Unfortunately, we cannot test this hypothesis with the data from the 2002 Pew survey, as the generational status question was only asked to Latino respondents in there. ${ }^{11}$ To confirm that Latinos are more trusting than other ethnic/racial groups, we estimate a multivariate model using the 2004 NAES data, where political trust is the dependent variable and explanatory variables consist of demographic and political indicators. ${ }^{12}$ Table 3 presents these estimates. These logit estimates confirm the bivariate distributions; Latinos are more likely to be politically trusting than Anglos. And consistent with the race and politics literature, we see that Blacks are more likely to have low trust in government when compared to Anglos. Our multivariate estimates from the 2004 NAES are in line with the patterns of political trust from the NES data and the Pew Hispanic Center, and thus serve to confirm this basic result.

\subsection{The Determinants of Political Trust for Latinos, Whites and Blacks}

While these findings confirm that Latinos are more politically trusting than other Americans, it still does not explain why this is so. The distributions given in Table 1 can once again provide us with several insights. When we examine levels of political trust by one's generational status, the

\footnotetext{
${ }^{10}$ The percentage of Asians who are foreign-born is somewhat comparable to Latinos. From 1990-2000, 39.5\% of Asians were foreign born, $28.3 \%$ from 1980-1989 and 16.2\% from 1970-1979.

${ }^{11}$ Also, because the sample of Asian respondents is so small $(\mathrm{N}=57)$, any conclusive statements of trust, by generational status, would have also been difficult to make had a question about generational status been posed to Asian respondents.

${ }^{12}$ We also estimated a similar model on the Pew data, which produced similar results. The reason why we present the Annenberg results is because it more closely follows Hetherington's model of the determinants of political trust. In particular, the Annenberg Survey included several questions pertaining to the economy, while the Pew did not.
} 
most politically trustful Latinos are those who have most recently arrived, and as we move towards more distant immigrant arrival, this high level of political trust gradually declines. At the opposite end of the political trust scale, those responding in the "never" category, a much larger percentage of fourth generation Latinos are distrustful when compared to earlier generations. Thus, a strong pattern emerges when we examine Latinos' rates of political trust by their generational status; those who have newly arrived in the U.S. tend to hold the highest levels of political trust, but those Latinos whose families have had a longer presence in the U.S. are more cynical and pessimistic towards the U.S. government.

Along with generational status, recall that both the classic and segmented assimilation theories place a strong emphasis on the impact of discrimination on an immigrant's attitudes towards government. As such, we need to control for the possible effects of a respondent's encounters with discrimination, as well as other predictors of trust like their demographic attributes and generational status. We use the 2002 Pew Hispanic Survey to estimate the coefficients of this model, since it includes information on respondents' experiences with discrimination and their generational status, while the 2004 NAES data do not. Table 4 presents these estimates and Table 5 provides the estimated marginal effects from these logit models. Estimating the model separately on Anglo, Black and Latino respondents makes it possible to compare the effect of the explanatory variables on the levels of political trust, by a respondent's ethnic/racial identity. For Latinos, we see that their financial situation, education level, ethnicity, experiences with discrimination and generational status help to explain their levels of political trust. As predicted, those who have had the longest presence in America, fourth-generation Latinos, are less likely to be politically trusting than the most recent arrivals, first-generation Latinos. A fourth-generation Latino is .06 less likely to be politically trusting than a first-generation Latino.

\section{[Tables 4 and 5 Go Here]}

A Latino's experience with discrimination also impacts their levels of political trust in the predicted direction. A Latino with no experience of discrimination is more likely to be politically trusting, relative to a Latino with some experience of discrimination. Likewise, a Latino who has 
encountered workplace discrimination is less likely to be politically trusting when compared to a Latino who has never encountered workplace discrimination. Interestingly, the effect of general discrimination on political trust is slightly greater than the effect of workplace discrimination (.04 versus .03). This may suggest that Latinos who have had any experiences with discrimination may project these encounters on their views towards the government. Moving on, one's educational level also helps to explain their political trust levels; Latinos with no high school degree are more likely to be politically trusting than college-educated Latinos. Those who are college-educated may be more cynical and critical of the government, relative to those with less schooling, as a function of their greater levels of knowledge of U.S. politics.

In terms of sub-group differences, we see that Cubans are more politically trusting than Puerto Ricans. Considering the large amount of federal assistance provided to Cubans both in the past and in the present (Garcia 1996) as well as their strong alliance with the Republican Party, it is understandable why they might have more faith in the federal government than would other Latino groups. Finally, one's economic evaluations influences their levels of political trust; a Latino who considers their financial situation to be the same, rather than worse when compared to a year ago, is more trusting in government (.03). For those who perceive their financial situation to have improved, relative to a year ago, are more likely to always trust the government by an even greater amount (.06). Consistent with the previous work on political trust, one's economic evaluations, in this case measured by their pocketbook finances, affects their levels of political trust.

For Anglos, their partisanship, financial situation and gender affect their levels of political trust. The largest factor driving their trust in government is their party identification; Republicans are more politically trusting than are Independents. Again, this is consistent with previous research that finds partisans to be more trusting of the current administration when it is their political party (Citrin 1974). In this case, those who identify themselves as Republicans, rather than as Independents, are more trusting of the current Republican administration. Economic evaluations also explain Anglos' trust in government. Those who view their financial situation as either better or the same are more trusting than those who perceive their financial situation to be worse. 
Turning to the estimates for Black respondents, personal finances, workplace discrimination and certain demographic traits impact their attitudes towards government. Those who are discriminated against in the workplace are less likely to be politically trusting than those with no experiences of workplace discrimination. Interestingly, while both general and workplace discrimination influenced Latinos' levels of political trust, only workplace discrimination affected Blacks' views towards the government. Workplace discrimination also has a bigger impact on the likelihood of being most trustful for African-Americans (-.05) than it did for Latinos (-.03).

The models examining the determinants of political trust for Anglos, Latinos and Blacks paint a very distinct picture of the factors influencing these groups' views and attitudes towards the government. While demographics play a role for all three ethnic/racial groups, we see that for Anglos, their partisanship plays a more significant role in influencing their levels of political trust than for Blacks and Latinos. Discrimination affects both Blacks and Latinos in how they view the government, but we see that for Latinos, their generational status and ethnic background also explain their levels of political trust. This finding is consistent with our hypothesis that Latinos, over time, are more trusting than Blacks and Anglos because of the constant influx of Latino immigrants, thereby boosting the percentage of the Latino population who are foreign-born.

\subsection{Political Trust and Latino Attitudes about Redistribution}

The variations in the levels of political trust amongst Americans may also give way to distinctions in their political behavior and attitudes. In light of Hetherington's research (2005), we focus on the impact of political trust on policies that are directly attributable to the federal government. Table 6 presents the logit estimates of the models examining the impact of political trust on individuals' opinions toward redistributive policies. Of these four policies, a Latino's trust in government is important in their attitudes toward school vouchers/tax credits and federally-sponsored health insurance. Consistent with Hetherington's findings, high levels of political trust positively influence a Latino's support of federally-sponsored policies. The coefficient on the variable that interacts a Latino respondent with his/her level of political trust is negative and statistically significant (- 
.81); thus a Latino with a high level of political trust is less likely to favor a reduction in health insurance spending than a non-Latino with a low level of political trust. This result supports our hypothesis; given that Latinos' levels of political trust are higher than it is for Anglos and Blacks, their high trust in government make them more supportive of federally-sponsored initiatives than non-Latinos. In addition to their high levels of trust, recall that approximately one out of three Latinos lack health insurance in the U.S.; such a combination makes it understandable why Latinos would be more supportive of federal spending on health insurance than would non-Latinos.

\section{[Table 6 Goes Here]}

Trust in government also determines one's support for tax credits/vouchers for schools. The coefficient on the variable that interacts a Latino respondent with their level of political trust is statistically significant and signed in the expected direction (-.26). Thus, a politically trusting Latino is less likely to oppose federal efforts at offering school tax credits or vouchers than a less politically trusting non-Latino. While school vouchers/tax credits are not redistributive policies in the classic sense, they are directly attributable to the federal government. This result is similar to Hetherington's findings on public support for affirmative action, where political trust plays a critical role in one's support for a policy which is closely linked to the federal government. Also, given the caliber of public education available to most Latinos, they may view school vouchers and tax credits as viable alternatives.

We next calculate first difference estimates to determine the impact of political trust on Latino's attitudes towards these two policies. To do so, we use a hypothetical Latino respondent by setting all variables other than political trust to their mean or mode. We then focus on several counterfactual scenarios: 1) when the respondent goes from never to sometimes trusting the government; 2) when the respondent goes from never to most of the time trusting the government; 3 ) when the respondent goes from never to always trusting the government.

For the first scenario, we estimate the hypothetical respondent's probability of opposing federal spending on health insurance/vouchers when he never trusts the government and then calculate the same probability when he trusts the government some of the time. The second scenario estimates 
the hypothetical respondent's probability of never trusting the government and then the probability when he trusts the government most of the time. Finally, the third counterfactual scenario calculates the probability of never trusting the government to always trustng the government. The difference between these two probabilities, for each of the scenarios, produce the first difference estimates. They are presented in Table 7 .

\section{[Table 7 Goes Here]}

These first difference estimates demonstrate the importance of political trust in a Latino's views on school vouchers and government efforts to assist the uninsured. As we expected, more trust in government leads to greater support for these federally-sponsored policies, though political trust has a larger impact on a Latino's attitudes towards school vouchers than it does for federally sponsored health insurance. For instance, we see that a Latino who goes from never to sometimes trusting the government decreases his likelihood of opposing federal spending on vouchers by .06. And when this hypothetical Latino goes from never to most of the time trusting the government, his probability of opposing federal spending on vouchers drops by .12 . The biggest impact of political trust on a Latino's policy views occurs when he shifts from being the least to the most politically trustful; this reduces his likelihood of opposing government spending on vouchers by .17. On the policy of federally-assisted health insurance, we see how political trust plays a smaller role on our hypothetical Latino's attitudes. Regardless of a change in one's levels of political trust, its greatest impact is minimal at .02. Nonetheless, we do find evidence that how trusting a Latino is in government affects their policy opinions and attitudes. And given that Latinos have greater trust

in government than for the rest of the American population, this may shape the overall distribution of American public opinion in the years to come.

\section{Conclusion}

At the onset of this paper, we presented a rather straightforward but perplexing empirical puzzle; why, over the last three decades, have Latinos been more trusting of government than Anglos or Blacks? Our answer to this puzzle rests on two factors - patterns of assimilation and immigration 
trends. First, we find strong evidence that a Latino's generational status plays a significant role in determining how politically trusting they are; first-generation Latinos are much more trusting of the federal government than are later-generation Latinos. The reason for this is straightforward; first-generation immigrants are generally more optimistic and enthusiastic about the economic opportunities that await them in their host country. As such, we expect their views and attitudes towards government to be more positive than those of later-generation immigrants. Classic assimilation theory also predicts that as immigrants become more acculturated and integrated into dominant society, their opinions will begin to mirror those of the majority, thereby gaining a more skeptical and cynical outlook of the federal government.

The second factor relates to immigration trends; according to the U.S. Census, the rate of Latino immigration has consistently increased from 1970-2000. Since the Latino population is being continually replenished with a large percentage of foreign-born individuals, Latinos' overall levels of political trust may be over-represented by the opinions and attitudes of the foreign-born population. And while Latinos' levels of political trust follow the general pattern of Anglos and Blacks, it is consistently higher over the time period that we focus on. Thus, when these two factors are combined, we see why Latinos are more politically trusting than Blacks and Anglos.

We also demonstrate the importance of political trust on Latinos' attitudes towards redistributive policies. More politically trusting Latinos supported government assistance in providing help to the uninsured as well as offering school vouchers and tax credits. Thus, the fact that Latinos' levels of political trust are higher than it is for Anglos and Blacks is non-trivial; political trust is a significant predictor of Latinos' policy views, particularly on those which they stand to benefit from.

These findings also present a number of implications for the future of American public opinion and policy-making. Given our result that Latinos' high levels of political trust positively affect their support for redistributive policies, along with projections that Latinos will comprise $25 \%$ of the U.S. population by 2025, we expect their support for redistributive policies to continue. This has the potential to change overall public opinion on a policy area that has becoming increasingly less 
popular in the past two decades. A gradual shift in public support towards redistributive policies may therefore be in place as a result of the changing demographic landscape of the American population. 


\section{References}

Abramson, Paul. 1983. Political Attitudes in America. San Francisco, Freeman Press.

Almond, Gabriel and Sydney Verba. 1963. The Civic Culture: Political Attitudes and Democracy in Five Nations. Princeton, Princeton University Press.

Baldasarre, Mark. 2004. PPIC Statewide Survey: Special Survey on Californians and their Future. Public Policy Institute of California, www.ppic.org.

Carey, Kevin. 2003. "The Funding Gap". The Education Trust.

Chan, S. 1997. "Effects of Attention to Campaign Coverage on Political Trust". International Journal of Public Opinion Research. 9: 286-296.

Citrin, Jack. 1974. "Comment: the Political Relevance of Trust in Government." American Political Science Review. 68: 973-988.

Citrin Jack and C. Muste. 1999. "Trust in Government" in Measures of Political Attitudes, editors, JP Robinson, PR Shaver and L Wrightsman. New York, Academic Press.

Citrin Jack and Donald P. Green. 1986. "Presidential Leadership and the Resurgence of Trust in Government". British Journal of Political Science. 16: 431-453.

Craig, SC. 1996. "The Angry Voter: Politics and Popular Discontent in the 1990s" in Broken Contract: Changin Relationships between Americans and their Government, edited by SC Craig. Boulder, CO, Westview Press.

Dahl, Robert. 1961. Who Governs? Democracy and Power in an American City. New Haven and London, Yale University Press.

Dawson, Michael. 1994. Behind the Mule: Race and Class in African-American Politics. Chicago, University of Chicago Press.

de la Garza, Rodolfo and Luis DeSipio. 1992. From Rhetoric to Reality: Latino Politics in the 1988 Elections. Boulder, CO, Westview Press.

Feldman S. 1983. "The Measurement and Meaning of Political Trust." Political Methodologist. 9:341-354.

Garcia, Maria Cristina. 1996. Havana USA: Cuban Exiles and Cuban Americans in South Florida, 1959-1994. Berkeley, University of California Press.

Garcia Bedolla, Lisa. 2005. Fluid Borders: Latino Power, Identity and Politics in Los Angeles. Berkeley, University of California Press.

Glazer, Nathan and Daniel P. Moynihan. 1970. Beyond the Melting Pot: The Negroes, Puerto Ricans, Jews, Italians and Irish of New York City. Cambridge, MA, MIT Press. 
Greeley, Andrew. 1971. Why Can't They Be Like Us? America's White Ethnic Groups. New York, E.P. Dutton.

Hajnal, Zoltan L. and Mark Baldassare. 2001. "Finding Common Ground: Racial and Ethnic Attitudes in California." San Francisco, Public Policy Institute of California.

Hardin, Russell. 2002. Trust and Trustworthiness. New York, Russell Sage Foundation.

Hero, Rodney. 1992. Latinos and the Political System: Two-Tiered Pluralism. Philadelphia, Temple University Press.

Hetherington, Marc J. 1998. "The political relevance of political trust" American Political Science Review . 92: 791-808.

Hetherington, Marc J. 1999. "The Effect of Political Trust on the Presidential Vote". American Political Science Review . 93: 311-326.

Hetherington, Marc J. 2005. Why Political Trust Matters: Declining Political Trust and the Demise of American Liberalism. Princeton, Princeton University Press.

Levi, Margaret and Laura Stoker. 2000. "Political Trust and Trustworthiness". Annual Review of Political Science. 3: 475-507.

Markus, Gregory B. 1979. "The Political Environment and the Dynamics of Public Attitudes: a panel study." American Journal of Political Science. 23: 338-359.

Michelson, Melissa. 2001. "Trust in Chicago Latinos". Journal of Urban Affairs. 23:323-334.

Michelson, Melissa. 2003. "The Corrosive Effect of Acculturation: How Mexican Americans Lose Political Trust". Social Science Quarterly. 84: 919-933.

Miller, A. 1974. "Political Issues and Trust in Government:1964-1970". American Political Science Review. 68: 951-972.

Parker, GR. 1989. "The Role of Constituent Trust in Congressional Elections." Public Opinion Quarterly. 53:175-196.

Pantoja, Adrian, Ricardo Ramirez and Gary M. Segura. 2001. "Citizens by Choice, Voters by Necessity: Patterns in Political Mobilization by Naturalized Latinos". Political Research Quarterly. 54: 729-750.

Patterson, Thomas E. 1994. Out of Order. New York, Knopf Press.

Portes, Alejandro and Ruben Rumbaut. 1996. Immigrant America: A Portrait. Berkeley, University of California Press.

Putnam, Robert. D. 2000. Bowling Alone: The Collapse and Revival of American Society. New York, Simon and Shuster. 
Romer, Daniel, Kate Kenski, Kenneth Winneg, Christopher Adasiewicz, and Kathleen Hall . 2006. Capturing Campaign Dynamics 200085 2004. Philadelphia, University of Pennsylvania Press.

Rosenstone, Steven J. and Hanson. 1993. Mobilization, Participation, and Democracy in America. New York, MacMillan Press.

Shingles, Richard D. 2001. "Black Consciousness and Political Participation: The Missing Link". American Political Science Review. 75: 76-91.

Stokes, Donald E. 1962. "Popular Evaluation of Government: an Empirical Assessment, in Ethics and Bigness: Scientific, Academic, Religious, Political and Military., edited by H. Cleveland and HD Lasswell. pp. 61-72. New York, Harper Press.

U.S. Census Bureau. 2002. www.census.gov.

Weatherford, MS. 1984. "Economic "stagflation" and Public Support for the Political System." British Journal of Political Science. 14: 187-205.

Williams JT. 1985. "Systematic Influences on Political Trust: the Importance of Perceived Institutional Performance." Political Methodologist. 11:125142.

Wolfinger, Raymond E. 1974. The Politics of Progress. New Jersey, Prentice-Hall. 


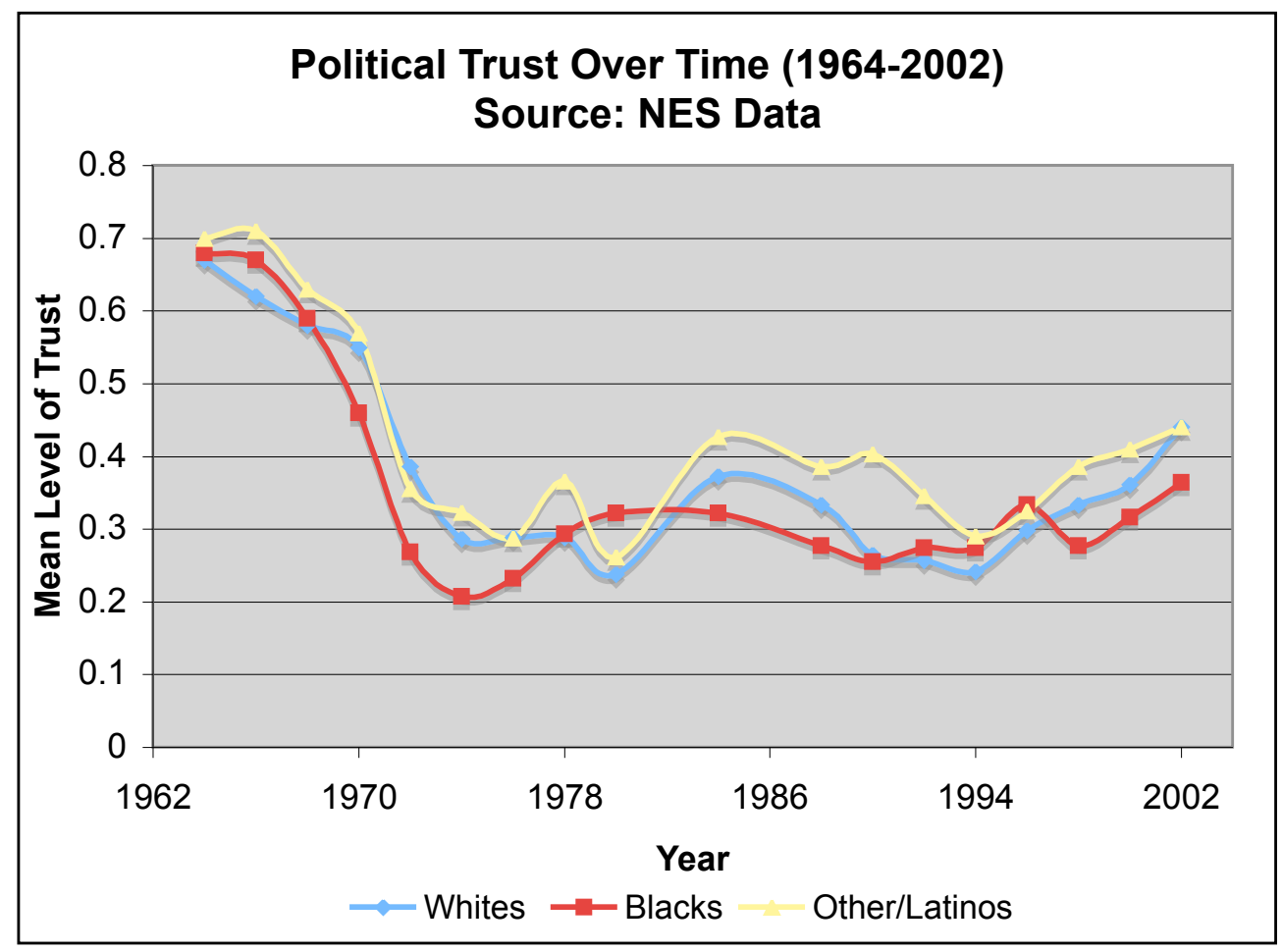




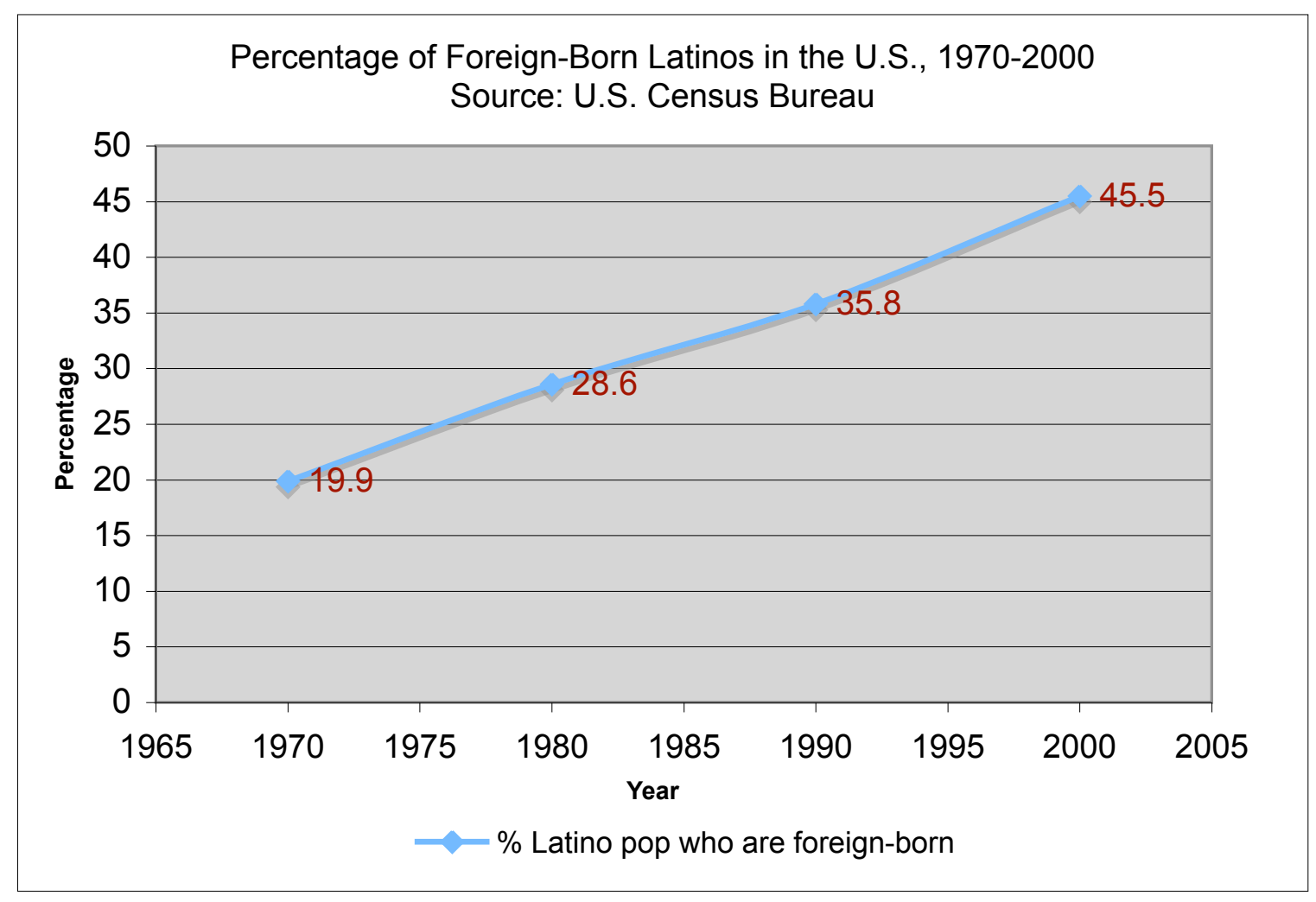




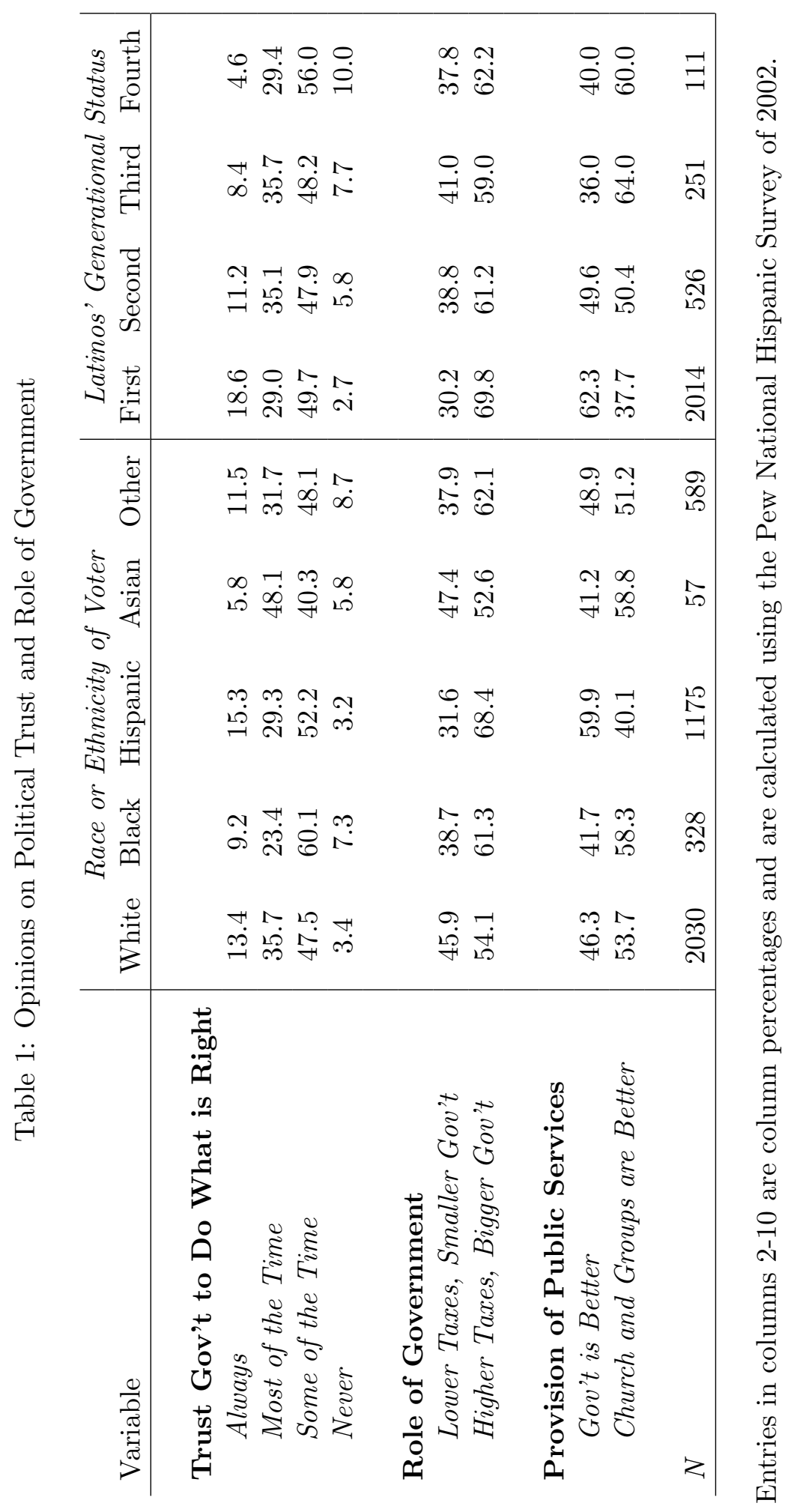


Table 2: Opinions on Political Trust: 2004 Elections

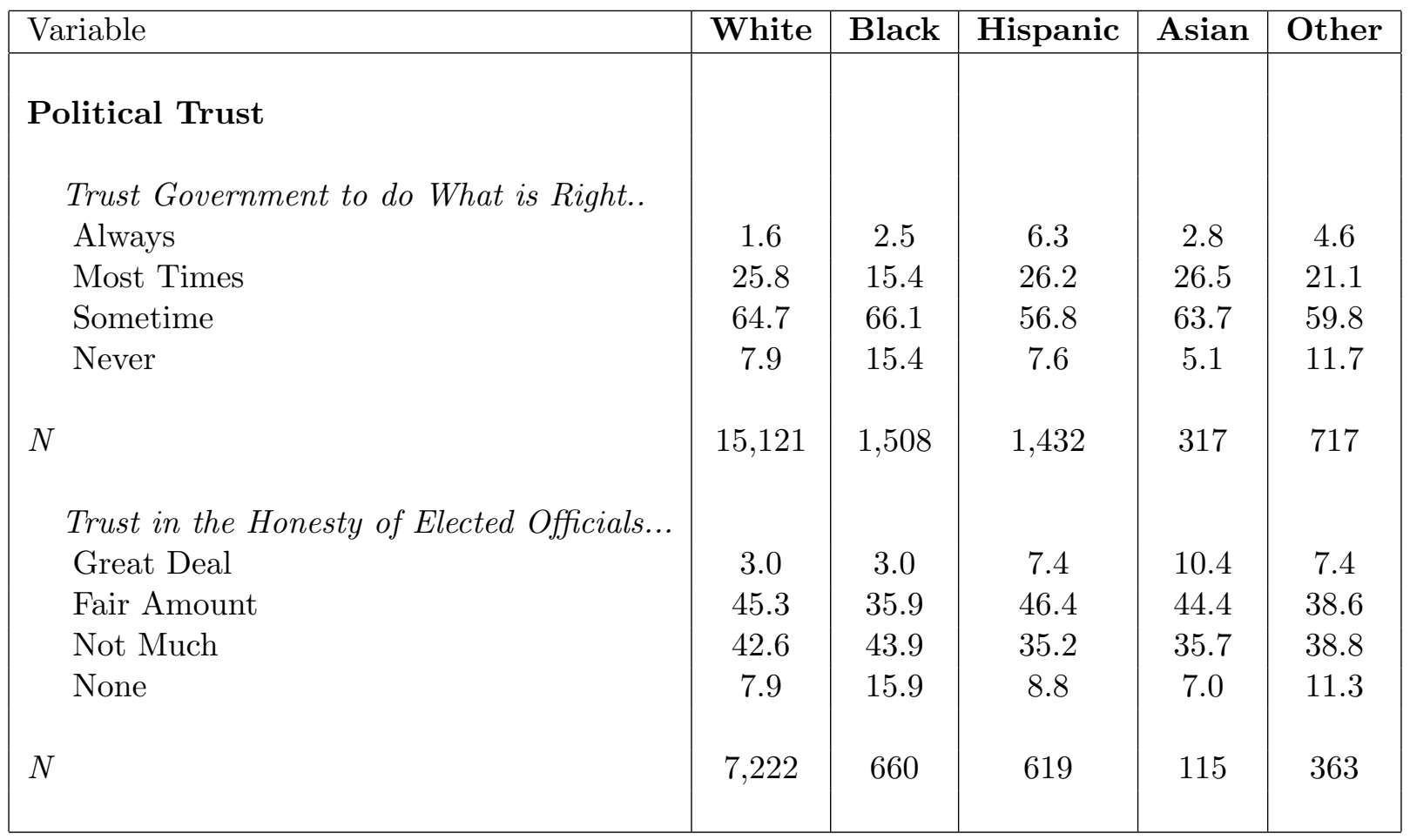

Source: 2004 Annenberg National Election Survey. Cell entries are column percentages. 
Table 3: Ordered Logit Estimates: Determinants of High Political Trust

\begin{tabular}{|c|c|}
\hline Variable & $\begin{array}{r}\text { Coefficient } \\
(\text { Std. Err.) }\end{array}$ \\
\hline \multicolumn{2}{|l|}{ Political and Demographic Variables } \\
\hline Female & $\begin{array}{c}0.05^{*} \\
(0.02)\end{array}$ \\
\hline Age & $\begin{array}{r}0.00 \\
(0.00)\end{array}$ \\
\hline Education & $\begin{array}{r}0.00 \\
(0.01)\end{array}$ \\
\hline Black $^{a}$ & $\begin{array}{l}-0.08^{*} \\
(0.04)\end{array}$ \\
\hline Latino $^{a}$ & $\begin{array}{l}0.26^{* *} \\
(0.04)\end{array}$ \\
\hline Liberal & $\begin{array}{c}0.00^{\dagger} \\
(0.01)\end{array}$ \\
\hline Democrat & $\begin{array}{l}0.13^{* *} \\
(0.03)\end{array}$ \\
\hline Republican & $\begin{array}{l}0.21^{* *} \\
(0.03)\end{array}$ \\
\hline \multicolumn{2}{|l|}{ Economic Indicators } \\
\hline Poor Economic Evaluation & $\begin{array}{l}-0.25^{* *} \\
(0.02)\end{array}$ \\
\hline Personal Finances Worse & $\begin{array}{l}-0.10^{* *} \\
(0.01)\end{array}$ \\
\hline Country Going in Right Direction & $\begin{array}{r}0.47^{* *} \\
(0.03)\end{array}$ \\
\hline $\mathrm{N}$ & 13730 \\
\hline Log-likelihood & -11321.45 \\
\hline
\end{tabular}

${ }^{a}$ The omitted category is Anglo respondents. 


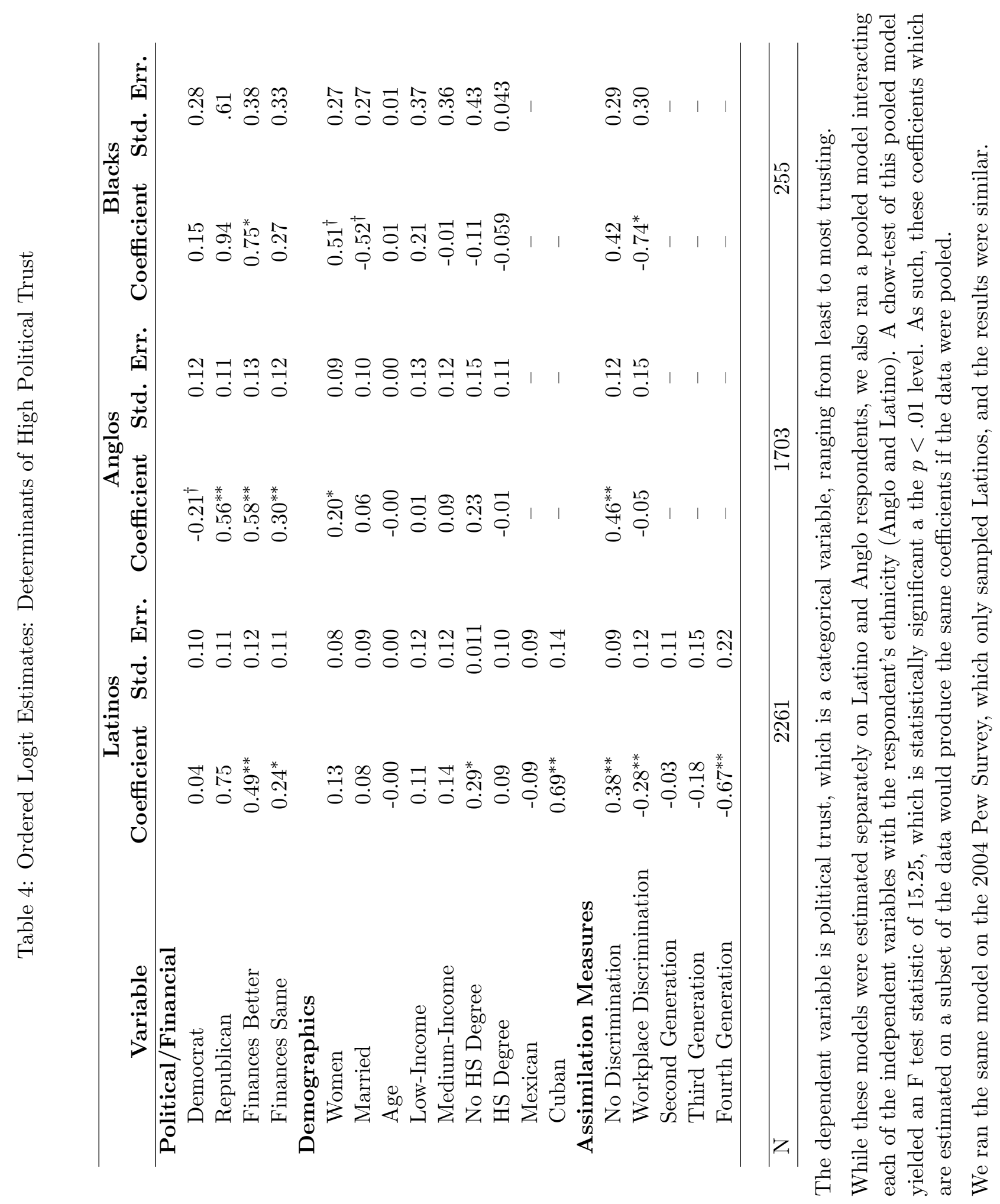




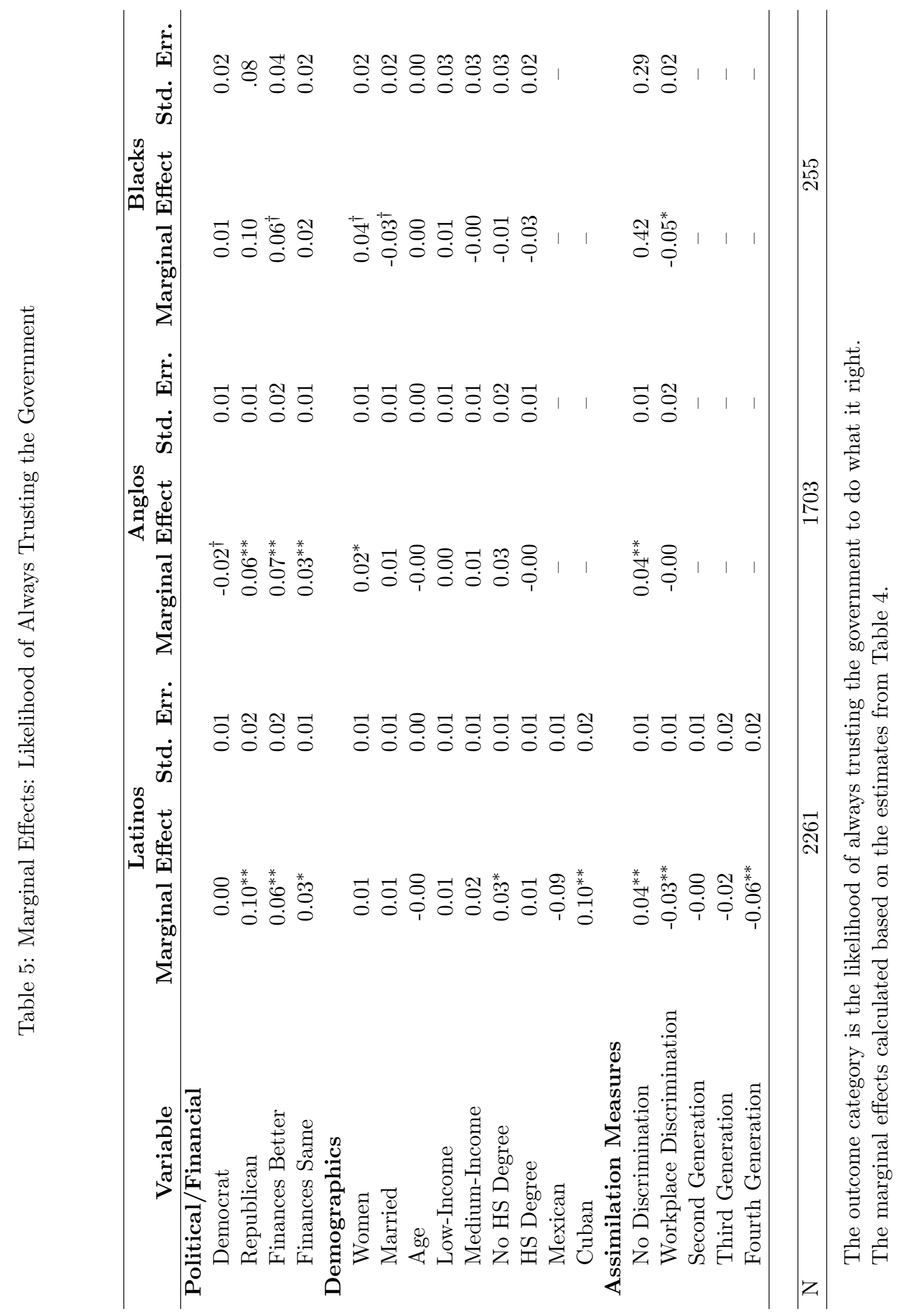




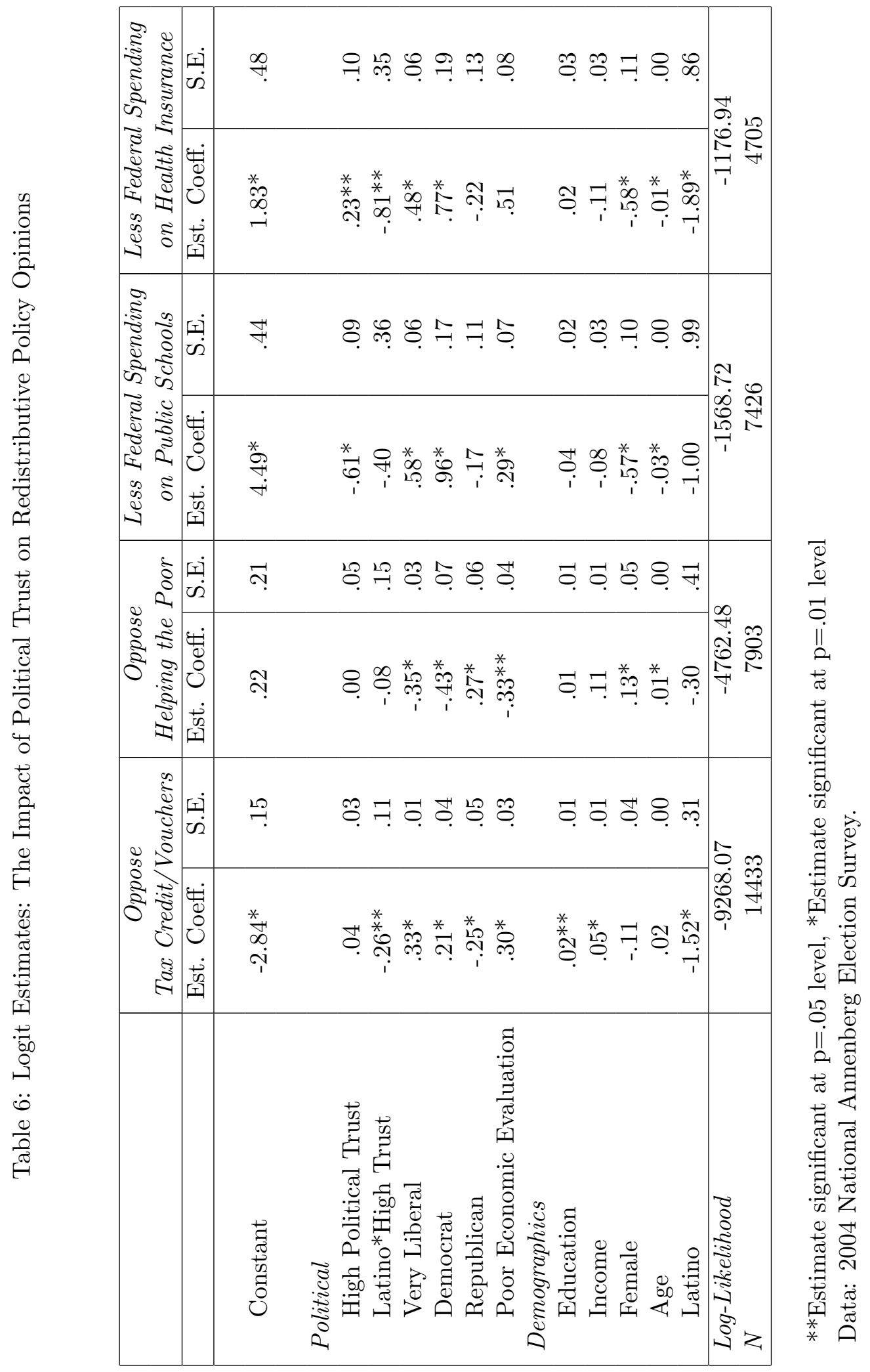




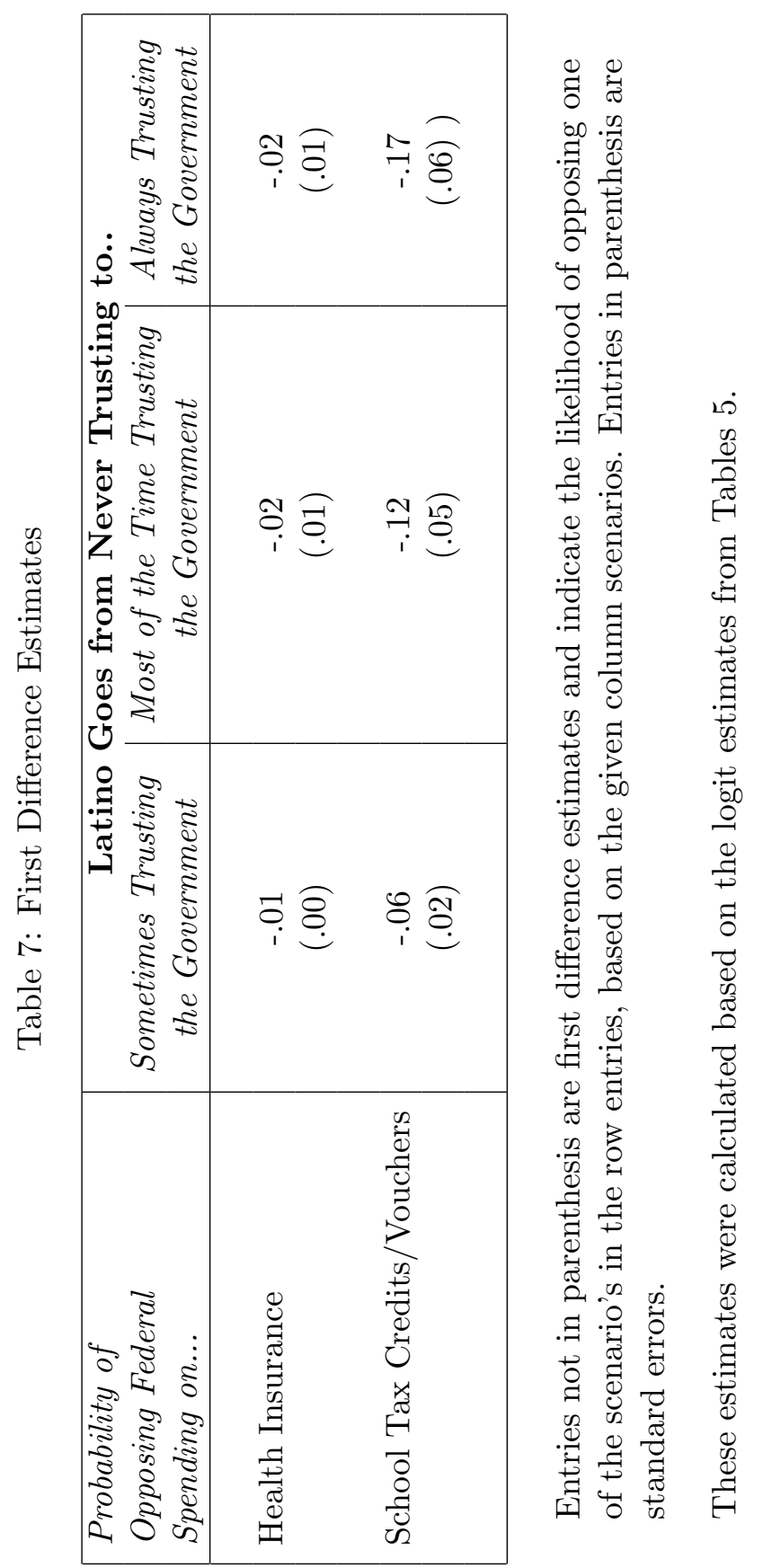

